\title{
Development of Dispersive Liquid-Liquid Microextraction Based on Solidification of Floating Organic Drop for the Sensitive Determination of Trace Copper in Water and Beverage Samples by Flame Atomic Absorption Spectrometry
}

\author{
Chunxia Wu, Bin Zhao, Yingli Li, Qiuhua Wu, Chun Wang, and Zhi Wang*
Key Laboratory of Bioinorganic Chemistry, College of Science, Agricultural University of Hebei, Baoding 071001, China
*E-mail: zhiwang1963@yahoo.com.cn
Received September 27, 2010, Accepted December 26, 2010

\begin{abstract}
A dispersive liquid-liquid microextraction based on solidification of floating organic droplet (DLLME-SFO) has been developed as a new approach for the extraction of trace copper in water and beverage samples followed by the determination with flame atomic absorption spectrometry. In the DLLME-SFO, 8-hydroxy quinoline, 1-dodecanol, and methanol were used as chelating agent, extraction solvent and dispersive solvent, respectively. The experimental parameters related to the DLLME-SFO such as the type and volume of the extraction and dispersive solvent, extraction time, sample volume, the concentration of chelating agent and salt addition were investigated and optimized. Under the optimum conditions, the enrichment factor for copper was 122. The method was linear in the range from 0.5 to $300 \mathrm{ng} \mathrm{mL}^{-1}$ of copper in the samples with a correlation coefficient $(r)$ of 0.9996 and a limit of detection of $0.1 \mathrm{ng} \mathrm{mL}^{-1}$. The method was applied to the determination of copper in water and beverage samples. The recoveries for the spiked water and beverage samples at the copper concentration levels of 5.0 and $10.0 \mathrm{ng} \mathrm{mL}^{-1}$ were in the range between $92.0 \%$ and $108.0 \%$. The relative standard deviations (RSD) varied from $3.0 \%$ to $5.6 \%$.
\end{abstract}

Key Words : Dispersive liquid-liquid microextraction based on solidification of floating organic droplet, Flame atomic absorption spectrometry, Copper, Water, Beverage

\section{Introduction}

In recent years, the determination of some trace elements in environmental and biological samples has received more and more attention. Trace levels of copper $(\mathrm{Cu})$ are well known to be an essential element for human beings and an active component of more than 30 enzymes, ${ }^{1}$ which can promote the growth and development of people and affect the function of endocrine and nervous system. However, exposure to high level of $\mathrm{Cu}$ may be toxic and has adverse effects on human health. For example, the excessive accumulation of $\mathrm{Cu}$ in the liver above a healthy limit could cause diarrhea, vomiting, transpiration, dermatosis, and, depending on its concentration, death from bleeding. ${ }^{2}$ In vitro studies have shown that cancer cells in a high copper environment are prone to proliferate into tumor. ${ }^{3}$ Moreover, for humans, the consumption of beverages and food are the main source for $\mathrm{Cu}^{4}$ Therefore, sensitive, selective and accurate analytical methods are desirable for the determination of trace amount of $\mathrm{Cu}$ in environmental and biological samples.

A variety of methods including electrothermal atomic absorption spectrometry (ETAAS), ${ }^{5}$ inductively coupled plasma-optical emission spectrometry (ICP-OES), ${ }^{6}$ graphite furnace atomic absorption spectrometry (GFAAS), ${ }^{7}$ and flame atomic absorption spectrometry (FAAS) ${ }^{8,9}$ have been developed for the determination of $\mathrm{Cu}$ in various sample matrices. Among them, FAAS is most widely used due to its low cost, easy operation, high sample throughput and good selectivity. However, sometimes, there are some difficulties for the direct determination of $\mathrm{Cu}$ by FAAS since its sensitivity is not sufficient for the samples with low abundance levels of $\mathrm{Cu} .{ }^{10}$ For this reason, an extraction and enrichment step is often required before the FAAS determination of the analyte.

Sample preparation is one of the most important and crucial steps in a whole analytical process. Up to now, several sample preparation methods have been developed for the determination of trace $\mathrm{Cu}$ from various sample matrices, including liquid-liquid extraction (LLE), ${ }^{11}$ solidphase extraction (SPE), ${ }^{12}$ cloud point extraction (CPE) ${ }^{13,14}$ membrane filtration ${ }^{15}$ and ion exchange. ${ }^{16}$ Nevertheless, these methods are time consuming, tedious, and often require large amounts of samples and toxic organic solvents. To overcome some drawbacks of the above-mentioned methods, solid-phase microextraction (SPME) and liquid-phase microextractions (LPME) have been developed as new attractive alternatives for sample preparations, which can save time, labor and solvent consumption, and therefore can improve the analytical performance of the procedure. Recently much attention is being paid to the development of different configurations of LPME, including single-drop microextraction (SDME), ${ }^{17}$ hollow fiber-based liquid-phase microextraction (HF-LPME) ${ }^{18}$ homogenous liquid-liquid extraction (HLLE) ${ }^{19}$ and dispersive liquid-liquid microextraction (DLLME). ${ }^{20}$ However, they also suffer from some draw- 
backs. For example, in SPME, its fiber is quite expensive, fragile and has limited lifetime. In addition, the sample carry-over is also a problem. ${ }^{21}$ In LPME, several disadvantages, such as the instability of liquid drop in SDME, air bubbles formation in HF-LPME, and long analysis time and relatively low precisions in some cases, are often encountered. ${ }^{22}$ In DLLME, high-density extraction solvents are required, such as chlorobenzene, chloroform and carbon tetrachloride, tetrachloromethane, etc., all of which are toxic and environmentally unfriendly. More recently, a new mode of liquid-phase microextraction based on solidification of floating organic droplet (LPME-SFO) was introduced by Yamini et al. ${ }^{23}$ in which, a small volume of the extractant with low density, low toxicity and proper melting point near room temperature was used. It is readily solidified at low temperatures and floated on the surface of aqueous solution, and thus can be collected easily. LPME-SFO has been used for the extraction of organic compounds and metal ions ${ }^{24,25}$ from water samples. The advantages of the LPME-SFO method are simplicity, low cost, environmental friendliness and high enrichment factor. However, the extraction time in LPME-SFO is usually prolonged and often needs about 3060 min. $^{25}$ To overcome this limitation, Leong et al. combined DLLME with LPME-SFO, developing a new microextraction technique termed dispersive liquid-liquid microextraction based on solidification of floating organic droplet (DLLME-SFO) ${ }^{26}$ In DLLME-SFO, an appropriate extraction solvent with low density, low toxicity and proper melting point near room temperature dissolved in a watermiscible dispersive solvent was rapidly injected into aqueous sample by syringe. A cloudy solution containing fine droplets of extraction solvent dispersed entirely in the aqueous sample phase was formed. After centrifugation, the extractant droplet floating on the top of the test tube can be easily solidified on an ice bath and taken out from the aqueous sample, then it melted immediately at room temperature and the melted organic solvent is used for analytes determination. In DLLME-SFO, the addition of an organic dispersive solvent, which is not used in LPME-SFO, can enhance the dispersion of the organic extraction solvent in the aqueous phase and accelerate the mass-transfer process of the analytes between the two immiscible phases, which, together with the large surface of contact between the two phases, leads to an increment in the extraction efficiency in a minimum amount of time. Therefore, the analysis time for DLLME-SFO can be as fast as DLLME, but is much shorter than LPME-SFO. ${ }^{27,28}$ In contrast to DLLME, the extractants often used in DLLME-SFO are of lower density than water and of lower toxicity. ${ }^{6}$ Furthermore, there is no need to use conical bottom glass tubes, which are easily damaged and hard to clean.

In this study, the application of the DLLME-SFO in combination with FAAS for the analysis of trace $\mathrm{Cu}$ in water and beverage samples was investigated. Various parameters that could affect the extraction efficiency were studied and optimized. The established method was found to be simple and have a good performance in terms of accuracy, linearity, repeatability and limits of detection (LODs). To the best of our knowledge, this paper may be the first report about the application of the DLLME-SFO technique for the extraction and determination of trace $\mathrm{Cu}$ in water and beverage samples.

\section{Experimental}

Reagents and Materials. All chemicals used were of analytical reagent grade. The stock standard solution of $\mathrm{Cu}^{2+}$ at a concentration of $1000 \mu \mathrm{g} \mathrm{mL}^{-1}$ was purchased from the National Institute of Standards of China (Beijing, China). Working standard solutions were prepared daily from the stock solutions by serial dilution. The chelating agent, 0.1 mol L ${ }^{-1}$ 8-hydroxy quinoline (Beijing Chemistry Reagent Company, Beijing, China), was prepared in methanol. 1dodecanol, 1-undecanol, $n$-hexadecane, and bromohexadecane were obtained from Beijing Chemical Reagents Company (Beijing, China). Sodium chloride $(\mathrm{NaCl})$, acetone, acetonitrile, tetrahydrofuran (THF), ethanol, and methanol were from Tianjin Fuchen Chemical Reagent Factory (Tianjin, China). The $\mathrm{pH}$ of solutions was adjusted with Britton-Robinson wide-ranging buffer solution, i.e., by mixing different proportions of $\mathrm{M} / 25$ mixture acids $\left(\mathrm{H}_{3} \mathrm{PO}_{4}\right.$, $\mathrm{CH}_{3} \mathrm{COOH}$ and $\left.\mathrm{H}_{3} \mathrm{BO}_{3}\right)$ and sodium hydroxide $\left(0.2 \mathrm{~mol} \mathrm{~L}^{-1}\right)$. The water used throughout the work was double-distilled on a SZ-93 automatic double-distiller purchased from Shanghai Yarong Biochemistry Instrumental Factory (Shanghai, China).

For water and beverage samples, tap water was taken from Laiyuan (Baoding, China), river water from Xiaoyingcun (Baoding, China), reservoir water from Xidayang (Baoding, China), Sprite, CocaCola, Green tea, and Black tea from Damaiyuan supermarket (Baoding, China). All the solvents and sample solutions were filtered through a $0.45-\mu \mathrm{m}$ membrane to eliminate particulate matter before analysis.

Instruments. A Hitachi Z-5000 atomic absorption spectrometer (Japan) equipped with Zeeman background correction and copper hollow-cathode lamp was used for absorbance measurements at the wavelength of $324.8 \mathrm{~nm}$ according to the instrument instruction. The instrumental parameters were adjusted according to the manufacturer's recommendations. All $\mathrm{pH}$ measurements were carried out using a $\mathrm{pH} 3-3 \mathrm{C}$ digital $\mathrm{pH}$ meter equipped with a combined glass-calomel electrode from Hangzhou Dongxing Instrument Factory (Hangzhou, China). A Model LD5-2A centrifuge from Beijing Jingli Instrument Factory (Beijing, China) was used for centrifugation.

Sample Preparation. Before the DLLME-SFO and subsequent FAAS measurements, water and beverage samples were filtrated through a $0.45-\mu \mathrm{m}$ membrane to remove the suspended particulate matter.

DLLME-SFO Procedure. For DLLME-SFO, an aliquot of $20.0 \mathrm{~mL}$ of sample solution and $2 \mathrm{~g} \mathrm{NaCl}$ were placed in a $25 \mathrm{~mL}$ screw cap glass test tube. The $\mathrm{pH}$ of the sample was adjusted to about 8 with $2.0 \mathrm{~mL}$ Britton-Robinson wideranging buffer $(\mathrm{pH} 8)$, and then, $2.5 \mathrm{mmol} \mathrm{L}^{-1} 8$-hydroxy quinoline were added into it. A mixture solution of $150 \mu \mathrm{L}$ 1-dodecanol (extraction solvent) and $1.25 \mathrm{~mL}$ methanol 
(dispersive solvent) was rapidly injected into the above solution, and then the mixture was vortexed for $1 \mathrm{~min}$. A cloudy solution that consists of very fine droplets of 1dodecanol dispersed into aqueous sample was formed, and the analytes were extracted into the fine droplets in a few seconds. After centrifugation at $3500 \mathrm{r} \mathrm{min}^{-1}$ for $3 \mathrm{~min}$, there was a liquid organic droplet floating on the top of the test tube due to its lower density than water. The glass tube was thereafter dipped into an ice bath for $5 \mathrm{~min}$. The floated organic droplet was solidified. Then the solidified solvent was transferred into a $1.5 \mathrm{~mL}$ conical vial in which it melted rapidly at room temperature. $350 \mu \mathrm{L}$ methanol was added to the extraction solution, and the copper concentration was determined by flame atomic absorption spectrometry.

\section{Results and Discussion}

In this research, DLLME-SFO combined with FAAS was developed for the preconcentration and determination of trace amounts of $\mathrm{Cu}$ in water and beverage samples. 8hydroxy quinoline, which is known to be one of the effective chelating reagents for $\mathrm{Cu}^{2+}$ ions, ${ }^{8,19,29}$ was selected as the chelating agent. In order to obtain the optimum DLLMESFO conditions, the influence of different experimental parameters including the type and volume of the extraction and dispersive solvent, extraction time, sample volume, the concentration of chelating agent and salt addition on the performance of DLLME-SFO were investigated.

In the experiment, $20.0 \mathrm{~mL}$ of double-distilled water spiked with $250 \mathrm{ng} \mathrm{mL}^{-1} \mathrm{Cu}^{2+}$ ions was used to study the extraction performance under different experimental conditions. All experiments were performed in triplicate and the means of the results were used in plotting the optimization curves. $\mathrm{Cu}$ standard solutions $\left(1-10 \mu \mathrm{g} \mathrm{mL}^{-1}\right)$ in nitric acid solution were prepared daily and their absorbance was read along with samples.

Selection of Extraction and Dispersive Solvent. Choosing an appropriate extraction solvent is of great importance to achieve good extraction efficiency of the target compounds. The extraction solvent in DLLME-SFO should fulfill the following requirements: it must be immiscible with water and can dissolve the analyte better than water to promote the extraction of the analytes. What's more, it should have low volatility, low toxicity, lower density than water and a low melting point around room temperature (in the range from 10 to $30^{\circ} \mathrm{C}$ ). Accordingly, four extraction solvents, i.e., 1-dodecanol, 1-undecanol, $n$-hexadecane, and bromohexadecane were investigated for the extraction of copper. On the other hand, dispersive solvent can also play an important role for the extraction performance. In DLLME-SFO, a selection of the dispersive solvent is also a key factor. It should be miscible with both water and the extraction solvent, and could form a well-dispersed solution when injected with the extractant into aqueous samples. Thus, acetone, methanol, THF, acetonitrile and ethanol were selected for the study. Due to the limited number of the organic extractants, all combinations of using 1-dodecanol,

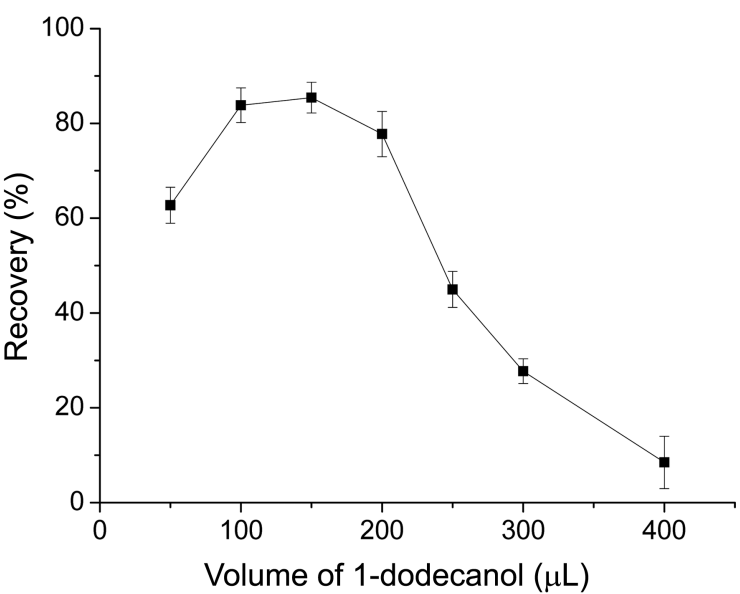

Figure 1. Effect of the volume of extraction solvent (1-dodecanol). Extraction conditions: sample volume, $20.0 \mathrm{~mL}$; extraction solvent, 1-dodecanol; dispersive solvent, $1.5 \mathrm{~mL}$ methanol; $\mathrm{pH}, 5.8$; 8hydroxy quinoline concentration, $5 \mathrm{mmol} \mathrm{L}^{-1}$; reaction time, 5 min; extraction time, $5 \mathrm{~min}$.

1-undecanol, $n$-hexadecane, and bromohexadecane as the extractant with acetone, methanol, ethanol, acetonitrile and THF as the dispersive solvent were investigated. The experiments showed that $n$-hexadecane and bromohexadecane can not be dissolved in any of the five dispersive solvents possibly due to their strong hydrophobicity. The best extraction efficiency for the target analytes was obtained when 1-dodecanol was used as extraction solvent and methanol as dispersive solvent. Based on the above results, 1-dodecanol and methanol were selected as the extraction and dispersive solvents for the subsequent studies.

Effect of Extraction Solvent Volume. In order to examine the effect of the volume of the extraction solvent, different volumes of 1-dodecanol ranging from 50 to $400 \mu \mathrm{L}$ were tested. It can be observed from Figure 1 that the extraction efficiency is increased by increasing the volume of 1-dodecanol up to $150 \mu \mathrm{L}$ and then decreased, which is probably because, as the volume of 1-dodecanol was increased above $150 \mu \mathrm{L}$, the concentration of the analytes in the extractant was decreased due to the dilution effect. Therefore, $150 \mu \mathrm{L}$ 1-dodecanol was chosen.

Effect of the Dispersive Solvent Volume. The volume of the dispersive solvent is also one of the important factors to be optimized in DLLME-SFO since the variation of the volume of the dispersive solvent may affect the dispersion of the extraction solvent in water solution, and thus affect the extraction efficiency. The influence of the volume of the dispersive solvent methanol was investigated by changing its volume from 0.5 to $2.5 \mathrm{~mL}$. The results in Figure 2 showed that when the volume of methanol was increased from 0.5 to $1.25 \mathrm{~mL}$, the extraction efficiency was increased, and then the extraction efficiency was slightly decreased. The reason for this could be explained as follows: when the volume of the dispersive solvent was too low, the extractant could not be well dispersed in the sample solution; on the other hand, when the volume of the dispersive solvent 


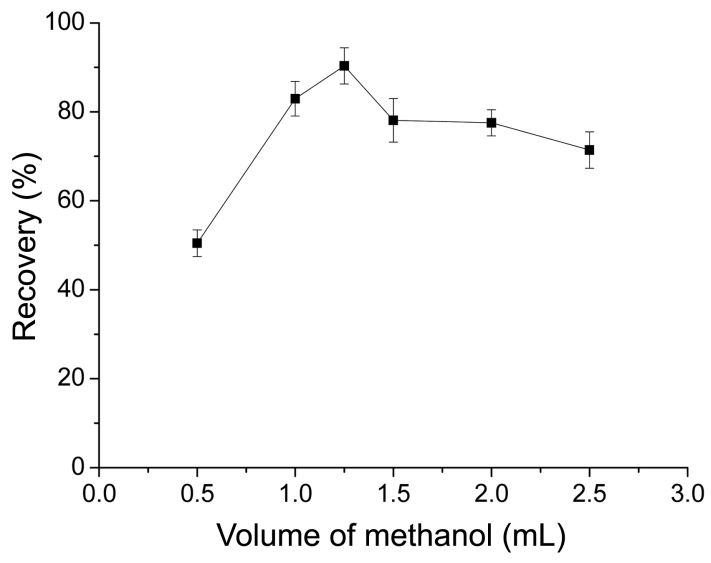

Figure 2. Effect of the volume of dispersive solvent (methanol). Extraction conditions: sample volume, $20.0 \mathrm{~mL}$; extraction solvent, $150 \mu \mathrm{L}$ 1-dodecanol; dispersive solvent, methanol; $\mathrm{pH}, 5.8 ; 8$ hydroxy quinoline concentration, $5 \mathrm{mmol} \mathrm{L}^{-1}$; reaction time, $5 \mathrm{~min}$; extraction time, $5 \mathrm{~min}$.

exceeded a certain value, the solubility of the analytes in water solution could be increased with further increase of the volume of the dispersive solvent, thus resulting in a decreased extraction efficiency. Based on the above experimental results, $1.25 \mathrm{~mL}$ of methanol was selected.

Effect of Sample Solution pH. The pH of the sample solution can play an important role in both the formation of the metal-chelate and the subsequent DLLME-SFO extraction. The influence of the $\mathrm{pH}$ on the complex formation and the extraction of $\mathrm{Cu}$ from water samples were investigated in the $\mathrm{pH}$ range from 2 to 12 when the other experimental conditions were kept constant. The results in Figure 3 indicated that the best extraction efficiency for $\mathrm{Cu}$ was obtained at $\mathrm{pH}$ about 8 . In this condition, hydrophilic $\mathrm{Cu}^{2+}$ is transformed to a neutral oxinate chelate which can be extracted into 1-dodecanol. Consequently, the $\mathrm{pH}$ of sample solution was selected as 8.0 for the subsequent studies.

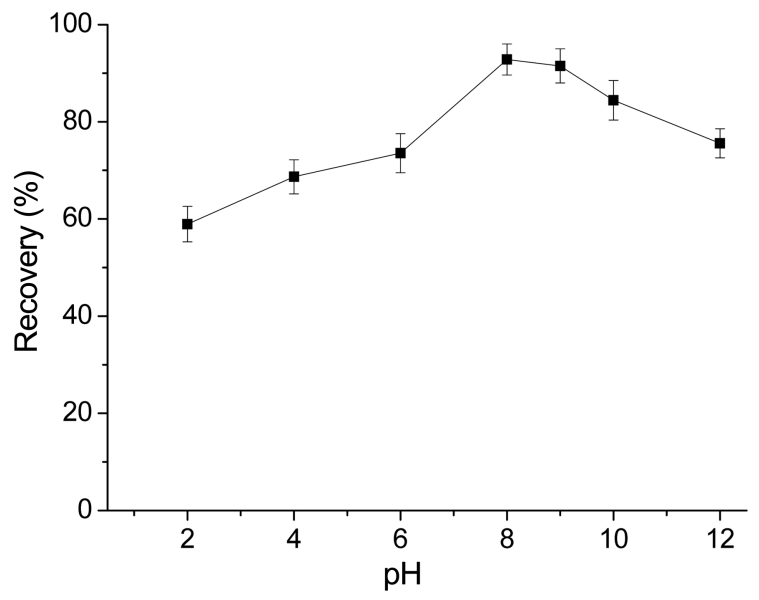

Figure 3. Effect of $\mathrm{pH}$ value on the extraction recovery of the copper. Extraction conditions: sample volume, $20.0 \mathrm{~mL}$; extraction solvent, $150 \mu \mathrm{L}$ 1-dodecanol; dispersive solvent, $1.25 \mathrm{~mL}$ methanol; 8-hydroxy quinoline concentration, $5 \mathrm{mmol} \mathrm{L}^{-1}$; reaction time, $5 \mathrm{~min}$; extraction time, $5 \mathrm{~min}$.

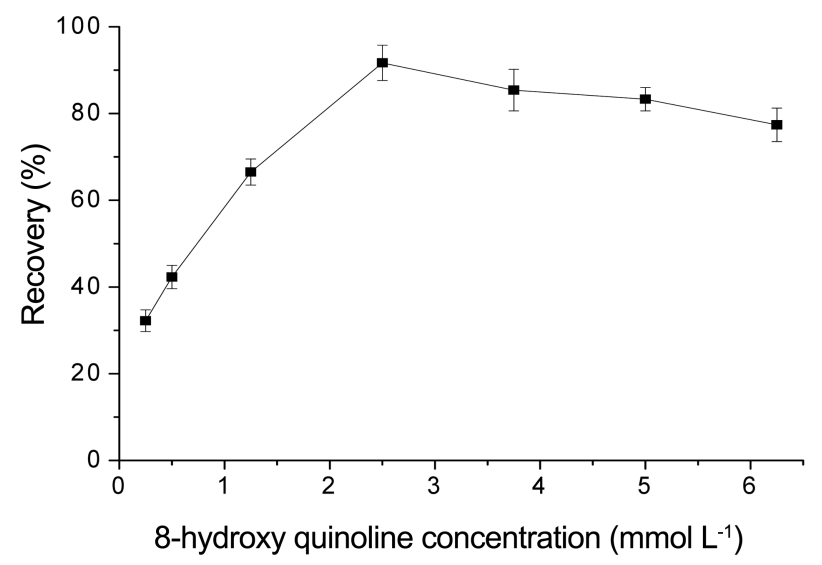

Figure 4. Effect of 8-hydroxy quinoline concentration on the extraction recovery of the copper. Extraction conditions: sample volume, $20.0 \mathrm{~mL}$; extraction solvent, $150 \mu \mathrm{L}$ 1-dodecanol; dispersive solvent, $1.25 \mathrm{~mL}$ methanol; $\mathrm{pH}, 8$; reaction time, $5 \mathrm{~min}$; extraction time, 5 min.

Effect of the Concentration of 8-Hydroxy Quinoline. The influence of the concentration of 8-hydroxy quinoline as a chelating agent was studied in the range from 0.25 to 7.5 mmol L $\mathrm{L}^{-1}$. As is shown in Figure 4, by the addition of increased amount of 8-hydroxy quinoline, the extraction recovery of the target ion was increased before $2.5 \mathrm{mmol} \mathrm{L}^{-1}$ and then was slightly decreased after that. At a low concentration of 8-hydroxy quinoline, the complexation was not complete and the extraction efficiency is low, hence the recovery was decreased. On the other hand, a high concentration of 8-hydroxy quinoline can cause a decreased extraction efficiency due to its saturation in the extraction solvent which resulted in its extraction into aqueous phase. In addition, at high concentration of 8-hydroxy quinoline, the background absorbance was increased. Hence, $2.5 \mathrm{mmol}$ $\mathrm{L}^{-1} 8$-hydroxy quinoline was chosen.

Effect of Reaction Time and Extraction Time. Reaction time, namely the time spent between the addition of 8hydroxy quinoline solution and the addition of the extraction solvent dissolved in dispersive solvent, may affect the extent of the formation of the metal-chelate, and thus affect the extraction efficiency. For this study, the reaction time was studied over the range from 1 to $10 \mathrm{~min}$. Extraction time is also an important factor in DLLME-SFO as in most other extraction procedures. In the DLLME-SFO, the extraction time was defined as the time interval elapsed between the start of addition of the mixture of extraction solvent and dispersive solvent to the sample and the time before centrifugation. The effect of extraction time on the extraction efficiency was examined by varying the extraction time from 1 to $9 \mathrm{~min}$. The results indicated that both the reaction and extraction time had no obvious impact on the extraction efficiency. This means that the equilibriums of both the metal-chelate reaction and the extraction process can be achieved quickly.

Effect of Salt Addition. Generally, the addition of salt can decrease the solubility of analytes in the aqueous phase and 
Table 1. Effect of interfering ions

\begin{tabular}{lc}
\hline \multicolumn{1}{c}{ Interfering ions } & $\begin{array}{c}\text { Tolerable concentration } \\
\text { (analyte: interfering ion) }\end{array}$ \\
\hline $\mathrm{Hg}^{2+}, \mathrm{Mn}^{2+}$ & $1: 1$ \\
$\mathrm{Ni}^{2+}, \mathrm{Fe}^{2+}, \mathrm{Fe}^{3+}$ & $1: 10$ \\
$\mathrm{Mg}^{2+}, \mathrm{Ca}^{2+}, \mathrm{K}^{+}, \mathrm{Zn}^{2+}, \mathrm{Pb}^{2+}, \mathrm{Al}^{3+}, \mathrm{Cr}^{3+}$, & $1: 100$ \\
$\mathrm{Na}^{+}, \mathrm{SO}_{4}^{2-}, \mathrm{NO}_{3}^{-}, \mathrm{Cl}^{-}$ & \\
\hline
\end{tabular}

The concentration of $\mathrm{Cu}^{2+}$ is $250 \mathrm{ng} \mathrm{mL}^{-1}$.

promote the transfer of the analytes towards the organic phase due to the salting-out effect, and thus, improve the extraction efficiency. In order to evaluate this effect, $\mathrm{NaCl}$ in the concentration range from 0 to $20 \%(\mathrm{w} / \mathrm{v})$ was added to the aqueous solution while the other conditions were kept constant. The results demonstrated that the extraction recovery was increased by increasing the $\mathrm{NaCl}$ concentration up to $10 \%$ and then decreased slightly. Hence, $10 \% \mathrm{NaCl}$ was selected.

Effect of Co-existing Ions. The interference refers to the competition of other heavy metals ions for the chelating agent and their subsequent coextraction with $\mathrm{Cu}$. In order to evaluate the applicability of the present procedure for the determination of $\mathrm{Cu}$ in real samples, interferences were studied over three concentration levels of each interfering ion (the ratio of the analyte to foreign ion: $1: 1,1: 10$ and $1: 100)$ in the presence of a constant concentration of analyte (250 $\mathrm{ng} \mathrm{mL} \mathrm{m}^{-1}$ ), and the results are shown in Table 1 . The tolerance limit was set as the amount of ion required to cause $10 \%$ deviation in the determination of $\mathrm{Cu}$. As can be seen in Table 1, most ions studied showed no significant interference with the formation of $\mathrm{Cu}$ and 8-hydroxy quinoline complex at 1:100 ratio. $\mathrm{Ni}^{2+}, \mathrm{Fe}^{2+}$, and $\mathrm{Fe}^{3+}$ do not interfere at $1: 1$ ratio but have serious interference effect at $1: 10$ ratio. For real samples, the contents of the above-mentioned coexisting species are usually lower than the tolerant concentration levels [5], therefore, the developed method should be applicable to the determination of $\mathrm{Cu}$.

\section{Application of DLMME-SFO in Real Samples.}

Linearity, Repeatability and LODS: The optimized DLLME-SFO method for the determination of $\mathrm{Cu}$ was evaluated in terms of linearity, precision, enrichment factor and LODs. Under the optimum conditions, the calibration graph exhibited linearity over the range of $0.5-300 \mathrm{ng} \mathrm{mL}^{-1}$ with the correlation coefficient $(r)$ of 0.9996 . The LOD, defined as $3 \mathrm{SB} / \mathrm{m}$ (where $\mathrm{SB}$ and $\mathrm{m}$ are the standard deviation of the blank and the slope of the calibration graph,

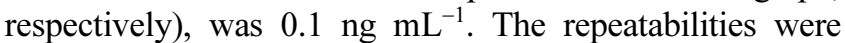
carried out by extracting and analyzing the spiked water samples at the concentration of each triazine at $10.0 \mathrm{ng} \mathrm{mL}^{-1}$ and the relative standard deviations (RSDs) for five replicate experiments varied from $3.0 \%$ to $5.6 \%$.

The enrichment factor $(E F)$ was defined as the ratio between the copper concentration in the floated phase $\left(C_{\text {floated }}\right)$ and the initial concentration of the analyte $\left(C_{0}\right)$ within the aqueous sample. ${ }^{26}$ In this study, in order to evaluate the effect of the above-mentioned factors, the $E F$ was intro- duced and used according to the Eqn. (1) as follows:

$$
E F=\frac{C_{\text {floated }}}{C_{0}}
$$

where $E F, C_{\text {floated }}$, and $C_{0}$ are the enrichment factor, the analyte concentration in the floating solvent and the initial analyte concentration in the aqueous samples, respectively. The enrichment factor was obtained as $122(n=3)$.

Real Samples Analysis: To evaluate the performance of the presented method, the extraction and determination of copper in different samples, i.e., water and beverages was performed under the optimum conditions established above. As a result, no residues of $\mathrm{Cu}$ were found in river water, reservoir water, and CocaCola. For tap water, Sprite and Green tea, the concentration of $\mathrm{Cu}$ were found to be at 7.2, 18.8 and $17.8 \mathrm{ng} \mathrm{mL}^{-1}$, respectively. The recoveries of the method (expressed as the mean percentage between the amounts determined and the ones spiked) for the water and beverage samples with the concentrations of $\mathrm{Cu}$ spiked at 5.0 and $10.0 \mathrm{ng} \mathrm{mL}^{-1}$ were in the range from 92.0 to $108.0 \%$ with the relative standard deviations (RSDs) of 4.1-6.8\%. The relevant results shown in Table 2 indicate a good performance of the DLLME-SFO method for the determination of $\mathrm{Cu}$ in water and beverage samples.

To further verify the accuracy of the method, the method

Table 2. Analytical results of copper determination in certified reference materials and spiked real samples with the DLLME-SFO method $(n=4)$

\begin{tabular}{|c|c|c|c|c|}
\hline Sample & $\begin{array}{l}\text { Certified } \\
\left(\mathrm{ng} \mathrm{mL}^{-1}\right)\end{array}$ & $\begin{array}{c}\text { Added } \\
\left(\text { ng } \mathrm{mL}^{-1}\right)\end{array}$ & $\begin{array}{l}\text { Found } \\
\left(\mathrm{ng} \mathrm{mL}^{-1}\right)\end{array}$ & $\begin{array}{c}\text { Recovery } \\
(\%)\end{array}$ \\
\hline \multirow{2}{*}{ GSBZ50009-88 } & $15 \pm 0.6$ & - & $14.3 \pm 0.4$ & 95.3 \\
\hline & $25 \pm 1.0$ & - & $24.1 \pm 0.9$ & 96.4 \\
\hline \multirow{2}{*}{ GSB07-1182-2000 } & $15 \pm 0.9$ & - & $15.7 \pm 0.7$ & 104.7 \\
\hline & $30 \pm 1.8$ & - & $28.1 \pm 1.6$ & 93.7 \\
\hline \multirow{3}{*}{ Tap water } & & 0 & $7.2 \pm 0.5$ & - \\
\hline & & 5 & $11.8 \pm 0.6$ & 92.0 \\
\hline & & 10 & $18.0 \pm 0.4$ & 108.0 \\
\hline \multirow{3}{*}{ River water } & & 0 & $\mathrm{nd}^{a}$ & - \\
\hline & & 5 & $4.9 \pm 0.5$ & 98.0 \\
\hline & & 10 & $9.5 \pm 0.4$ & 95.0 \\
\hline \multirow{3}{*}{ Reservoir water } & & 0 & $\mathrm{nd}^{a}$ & - \\
\hline & & 5 & $4.7 \pm 0.4$ & 94.0 \\
\hline & & 10 & $9.9 \pm 0.7$ & 99.0 \\
\hline \multirow{3}{*}{ Sprite } & & 0 & $18.8 \pm 0.5$ & - \\
\hline & & 5 & $23.6 \pm 0.6$ & 96.0 \\
\hline & & 10 & $29.0 \pm 0.6$ & 102.0 \\
\hline \multirow{3}{*}{ CocaCola } & & 0 & $\mathrm{nd}^{a}$ & - \\
\hline & & 5 & $4.8 \pm 0.5$ & 96.0 \\
\hline & & 10 & $9.4 \pm 0.6$ & 94.0 \\
\hline \multirow{3}{*}{ Green tea } & & 0 & $17.8 \pm 0.6$ & - \\
\hline & & 5 & $22.9 \pm 0.4$ & 102.0 \\
\hline & & 10 & $27.0 \pm 0.4$ & 92.0 \\
\hline \multirow{3}{*}{ Black tea } & & 0 & $\mathrm{nd}^{a}$ & - \\
\hline & & 5 & $4.8 \pm 0.5$ & 96.0 \\
\hline & & 10 & $9.4 \pm 0.5$ & 94.0 \\
\hline
\end{tabular}

\footnotetext{
${ }^{a}$ nd: not detected. ${ }^{b} \mathrm{R}$ : recovery of the method.
} 
Table 3. Comparison of DLLME-SFO with other sample preparation techniques for the determination of the copper

\begin{tabular}{|c|c|c|c|c|c|c|c|c|}
\hline Methods & Chelating agent & 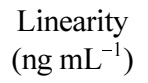 & $\begin{array}{c}\text { LOD } \\
\left(\text { ng } \mathrm{mL}^{-1}\right)\end{array}$ & $\begin{array}{l}\text { RSD } \\
(\%)\end{array}$ & $\mathrm{EF}$ & $\begin{array}{l}\text { Extraction } \\
\text { time (min) }\end{array}$ & Samples & References \\
\hline $\mathrm{CPE}$ & $\mathrm{DDTP}^{a}$ & $5-200$ & 0.94 & 3 & 25 & 20 & water, serum, hair & 13 \\
\hline CPE & $\mathrm{PDBDM}^{b}$ & $10-260$ & 0.6 & 1 & 30 & 15 & $\begin{array}{c}\text { vegetable, } \\
\text { liver, meat, water }\end{array}$ & 14 \\
\hline CPE & BHAPPDI $^{c}$ & $0.1-1300$ & 0.06 & 1.8 & 20 & 15 & water & 8 \\
\hline HLLE & 8- $\mathrm{QH}^{d}$ & $10-2000$ & 1.74 & 7.6 & 25 & 10 & water & 19 \\
\hline SPE & $\mathrm{N}^{e}$ & $1.0-4000$ & 1.0 & 2.4 & 400 & 60 & water & 12 \\
\hline SPE & DCPIMI $^{f}$ & $10-340$ & 1.9 & 2.1 & 35 & $>60$ & $\begin{array}{l}\text { quince, } \\
\text { lottus }\end{array}$ & 30 \\
\hline HF-LPME & 8-QH & $10-5000$ & 4.0 & 5.7 & 551 & 30 & water & 9 \\
\hline DLLME & 8-QH & $50-2000$ & 3 & 5.1 & 42 & - & water & 29 \\
\hline DLLME & - & $1.0-600$ & 0.5 & 1.4 & - & - & water & 31 \\
\hline DLLME-SFO & 8-QH & $0.5-300$ & 0.1 & 4.6 & 122 & A few seconds & water, beverage & This method \\
\hline
\end{tabular}

${ }^{a}$ DDTP: diethyldithiophosphate. ${ }^{b}$ PDBDM: 4-(Phenyl diazenyl) benzene-1,3-diamine/Triton X-114. ${ }^{c}$ BHAPPDI: $N$, $N$ '-bis(2-hydroxyacetophenone)1,2-propanediimine. ${ }^{8}$-QH: 8-hydroxy quinoline. ${ }^{e} \mathrm{~N}: N, N$-(4-methyl-1,2-phenylene)diquinoline-2-carboxamide. ${ }^{f}$ DCPIMI: 3-((2,6-dichlorophenyl)(1H-indol-3-yl)methyl)-1H-indole

was then applied to the determination of $\mathrm{Cu}$ in National Standard Reference Material for Environment Water (GSBZ50009-88 and GSB07-1182-2000). The results are presented in Table 2. They are in good agreement with the certified values, suggesting that. this new method should be reliable for the determination of $\mathrm{Cu}$ in water and beverage samples.

Comparison of DLLME-SFO with Other Sample Preparation Techniques: The performance of the presented DLLME-SFO method was compared with the other reported methods (the relevant data are listed in Table 3). As can be seen from Table 3, the DLLME-SFO method has comparable linearity range, LODs and RSDs with, and in some cases is better than those of the other reported extraction methods. However, it requires much shorter extraction time than either SPE or HF-LPME. The EF for the determination of $\mathrm{Cu}$ in this method is also better than those by most of the other reported methods. Furthermore, this DLLME-SFO is easy to operate without the need of any special instruments. The method is indeed simple, efficient, and environmentally friendly, and could be suitable for the routine analysis of the trace $\mathrm{Cu}$ ions in water and beverage samples.

\section{Conclusions}

In this study, DLLME-SFO coupled with FAAS has been successfully applied for the extraction and determination of $\mathrm{Cu}$ in water and beverage samples with relatively high sensitivity and good repeatability. Compared with other conventional sample preparation methods, the combination of DLLME and SFO offers advantages such as simplicity, low cost, ease of operation, fast analysis, minimum use of toxic organic solvent and high enrichment factor. Furthermore, this technique is compatible with a wide range of anaytes and analytical instruments, including spectroscopic and chromatographic methods. It can be concluded that DLLME-SFO can become a good alternative for the analysis of $\mathrm{Cu}$ in aqueous samples such as tap water and beverage.

Acknowledgments. This research was supported by the Natural Science Foundations of Hebei (B2010000657) and the Scientific Research Foundation of Agricultural University of Hebei (FS2200905).

\section{References}

1. Kazi, T. G.; Jalbani, N.; Kazi, N.; Jamali, M. K.; Arain, M. B.; Afridi, H. I.; Kandhro, A.; Pirzado, Z. Renal Fail. 2008, 30, 737.

2. Parmeggiani, L. In Proceedings of the 3rd International Labor Organization; Geneva, 1983; 1, 574.

3. Yaman, M. Curr. Med. Chem. 2006, 13, 2513.

4. Panahi, H. A.; Karimi, M.; Moniri, E.; Soudi, H. Afr. J. Pure Appl. Chem 2008, 2, 96.

5. Chen, X. W.; Huang, L. L.; He, R. H. Talanta 2009, 78, 71.

6. Yamini, Y.; Rezaee, M.; Khanchi, A.; Faraji, M.; Saleh, A. J. Chromatogr. A 2010, 1217, 2358.

7. Dadfarnia, S.; Salmanzadeh, A. M.; Shabani, A. M. H. Anal. Chim. Acta 2008, 623, 163.

8. Fathi, S. A. M.; Yaftian, M. R. J. Colloid Interface Sci. 2009, 334, 167.

9. Es'haghi, Z.; Azmoodeh, R. Arabian J. Chem. 2010, 3, 21.

10. Fathi, S. A. M.; Yaftian, M. R. J. Hazard. Mater 2009, 164, 133.

11. Diniz, M. C. T.; Filho, O. F.; Rohwedder, J. J. R. Anal. Chim. Acta 2004, 525, 281.

12. Rezaei, B.; Sadeghi, E.; Meghdadi, S. J. Hazard. Mater 2009, $168,787$.

13. Manzoori, J. L.; Bavili-Tabrizi, A. Microchem. J. 2002, 72, 1.

14. Shokrollahia, A.; Ghaedi, M.; Hossaini, O.; Khanjaria, N.; Soylak, M. J. Hazard. Mater. 2008, 160, 435.

15. Divrikli, U.; Kartal, A. A.; Soylak, M.; Elci, L. J. Hazard. Mater. 2007, 145, 459.

16. Kunio, O.; Masea, M.; Fumihiko, Y.; Isoshi, N.; Ryoei, I. Analyst 1990, 115, 23.

17. López-Blanco, C.; Gómez-Álvarez, S.; Rey-Garrote, M.; CanchoGrande, B.; Simal-Gándara, J. Anal. Bioanal. Chem. 2005, 383, 557.

18. Zhang, J.; Lee, H. K. J. Chromatogr. A 2006, 1117, 31.

19. Farajzadeh, M. A.; Bahram, M.; Zorita, S.; Mehr, B. G. J. Hazard. Mater. 2009, 161, 1535. 
20. Rezaee, M.; Assadi, Y.; Milani, H. M. R.; Aghaee, E.; Ahmadi, F.; Berijani, S. J. Chromatogr. A 2006, 1116, 1.

21. Prosen, H.; Zupanèiè-Kralj, Z. Trends Anal. Chem. 1999, 18, 272.

22. Ahmadi, F.; Assadi, Y.; Hosseini, S. M. R. M.; Rezaee, M. J. Chromatogr. A 2006, 1101, 307.

23. Khalili, Z. M. R.; Yamini, Y.; Shariati, S.; Jönsson, J. Å. Anal. Chim. Acta 2007, 585, 286.

24. Wang, Y. Y.; Zhao, G. Y.; Zang, X. H.; Wang, C.; Wang, Z. Chin. J. Anal. Chem. 2010, 38, 1517.

25. Sahin, C. A.; Tokgöz, I. Anal. Chim. Acta 2010, 667, 83.

26. Leong, M. I.; Huang, S. D. J. Chromatogr. A 2008, 1211, 8.
27. Xu, H.; Ding, Z.; Lv, L.; Song, D.; Feng, Y. Q. Anal. Chim. Acta 2009, 636, 28.

28. Jian, Y. Y.; Hu, Y.; Wang, T.; Liu, J. L.; Zhang, C.; Li, Y. Chin. J. Anal. Chem. 2010, 38, 62.

29. Farajzadeh, M. A.; Bahram, M.; Mehr, B. G.; Jönsson, J. Å. Talanta 2008, 75, 832 .

30. Ghaedi, M.; Niknam, K.; Taheri, K.; Hossainian, H.; Soylak, M. Food Chem. Toxicol 2010, 48, 891.

31. Mohammadi, S. Z.; Afzali, D.; Baghelani, Y. M. Anal. Chim. Acta 2009, 653, 173 . 